\title{
How Long Will I Be Blue? Prolonged Skin Staining Following Sentinel Lymph Node Biopsy Using Intradermal Patent Blue Dye
}

Metehan Gumus $^{\mathrm{a}}$ Hatice Gumus ${ }^{\mathrm{b}}$ Sue E. Jones ${ }^{\mathrm{c}}$

Peter A. Jones ${ }^{c} \quad$ Ali R. Sever ${ }^{d}$ Jennifer Weeks ${ }^{d}$

aDepartment of General Surgery,

${ }^{b}$ Department of Radiology, Dicle University, Medical School, Yenişehir, Diyarbakır, Turkey

'Department of Surgery,

${ }^{\mathrm{d} D e p a r t m e n t}$ of Radiology, Maidstone Hospital, Hermitage Lane, Maidstone, United Kingdom

\section{Keywords}

Axillary staging - Sentinel lymph node biopsy .

Skin discoloration - Patent blue

\section{Summary}

Background: Blue dye used for sentinel lymph node biopsy (SLNB) in breast cancer patients may cause prolonged skin discoloration at the site of injection. The aim of this study was to assess the duration of such skin discoloration. Patients and Methods: 236 consecutive patients who had undergone breast conserving surgery and SLNB for breast cancer were reviewed prospectively from January 2007 to December 2009. Results: Of the 236 patients, 2 had undergone bilateral surgery, and 41 had been examined in consecutive yearly reviews. Blue discoloration remained visible at the injection site after 12,24 , and $>36$ months in $36.5,23.6$, and $8.6 \%$ of the patients, respectively. Conclusion: The use of patent blue for identification of the sentinel lymph node in patients undergoing breast cancer surgery may result in prolonged discoloration of the skin at the injection site.

\section{Introduction}

Axillary lymph node status has been shown to be the most important prognostic indicator in patients with invasive breast cancer [1]. Sentinel lymph node biopsy (SLNB) is a less invasive alternative to axillary lymph node dissection (ALND) for staging in clinically node-negative early breast cancer. Many

\author{
Schlüsselwörter \\ Staging der Axilla · Sentinel-Knoten-Biopsie . \\ Hautverfärbung · Patentblau
}

\section{Zusammenfassung}

Hintergrund: Der für die Sentinel-Knoten-Biopsie bei Mammakarzinom-Patientinnen verwendete blaue Farbstoff kann längerfristige Hautverfärbungen im Injektionsbereich verursachen. Ziel dieser Studie war es, die Dauer derartiger Hautverfärbungen zu bestimmen. Patientinnen und Methoden: 236 aufeinanderfolgende Mammakarzinom-Patientinnen, bei denen eine brusterhaltende Operation und Sentinel-Knoten-Biopsie durchgeführt worden waren, wurden von Januar 2007 bis Dezember 2009 prospektiv untersucht. Ergebnisse: Bei 2 der 236 Patientinnen war eine bilaterale chirurgische Behandlung erfolgt, und 41 wurden im Rahmen jährlicher Nachuntersuchungen beurteilt. Blaue Verfärbungen im Injektionsbereich waren nach 12, 24 bzw. > 36 Monaten bei 36,5, 23,6 bzw. 8,6\% der Patientinnen weiterhin sichtbar. Schlussfolgerung: Die Anwendung von Patentblau zur Identifikation des Sentinellymphknotens bei chirurgisch behandelten Mammakarzinom-Patientinnen kann zur längerfristigen Verfärbung der Haut im Injektionsbereich führen.

studies have shown improved outcomes with less impairment of shoulder movement, lymphedema, and sensory deficit [24]. A combination of radioisotope and blue dye has been shown to provide the highest rates of sentinel lymph node identification $[1,5,6]$. SLNB provides an adequate staging while reducing both morbidity and hospitalization costs compared to ALND. This has led to the widespread use of this

\section{KARGER}

Fax +497614520714

Information@Karger.com

www.karger.com

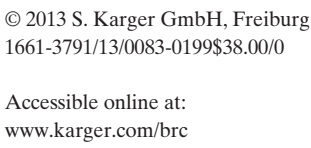

Assoc. Prof. Dr. Metehan Gumus, MD

Department of General Surgery

Medical School

Dicle University

Yenișehir 21280, Diyarbakır, Turkey

metehangumus@yahoo.com 


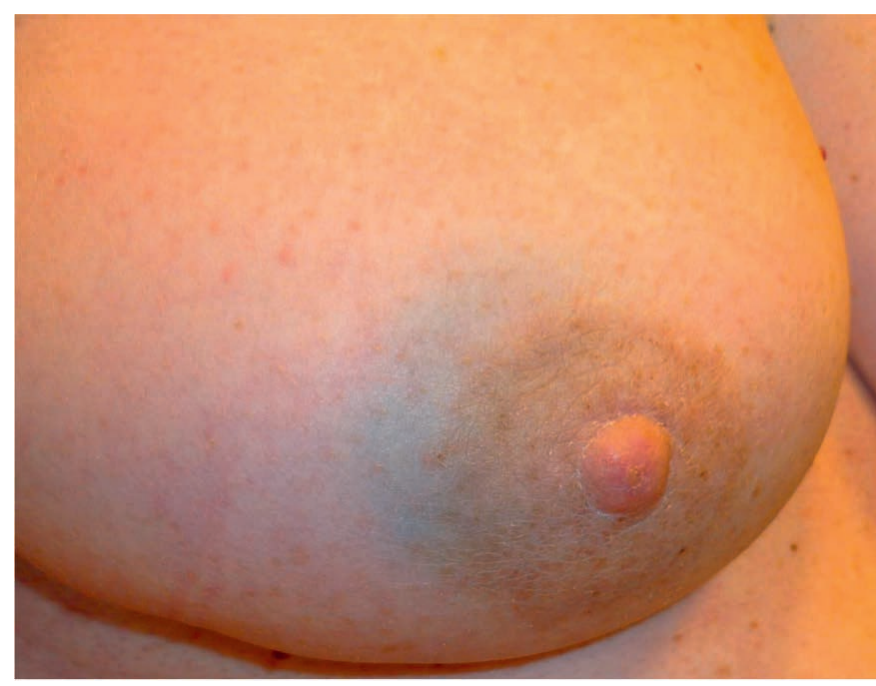

Fig. 1. Grade 1 discoloration in a 68-year-old patient with grade 2 invasive ductal carcinoma. 2 years following injection of blue dye, faint skin staining can still be identified.

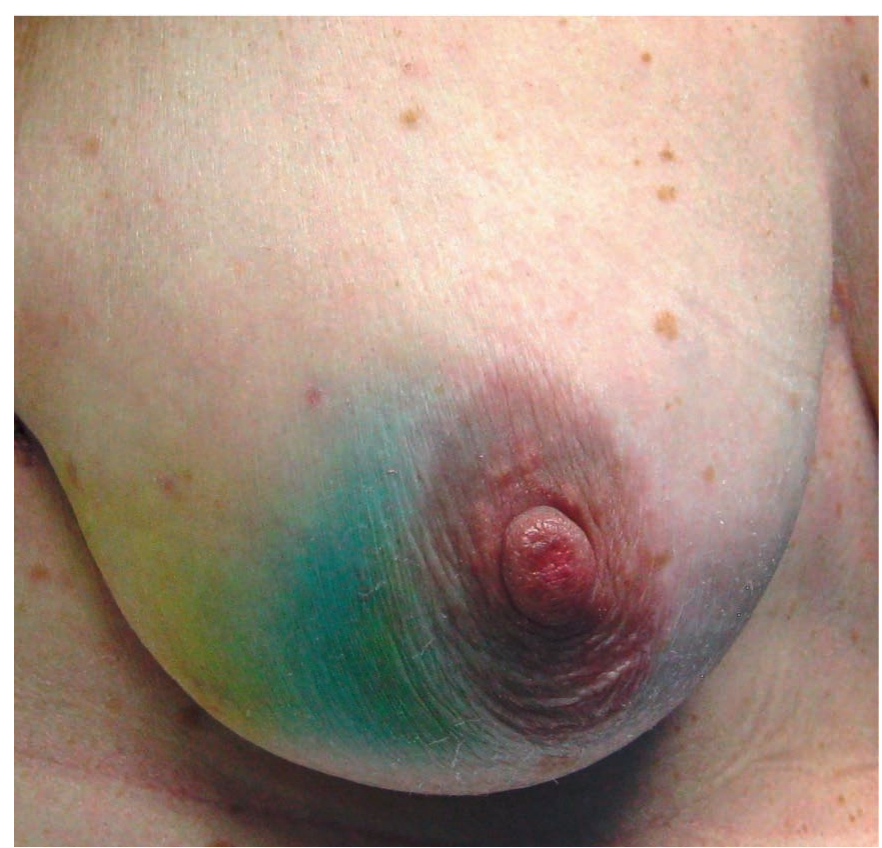

Fig. 2. Grade 3 discoloration in a 65 -year-old patient with grade 2 invasive ductal carcinoma. Marked blue staining is visible 1 week after injection. technique [7]. Patent blue dye (Bleu Patente V 2.5\%, Laboratoire Guerbet, Aulnay-sous-Bois, France) is usually used for SLNB. Patent blue has a specific binding capacity to proteins, enabling it to travel readily through the breast lymphatics [8]. The blue dye may cause several adverse reactions, including anaphylactic shock [1,9-12] and misleading intraoperative decrease in pulse oximeter readings $[13,14]$. Combined with radioisotope, intradermal injection of patent blue allows a 96-99\% rate of SLN identification [15]. Prolonged skin discoloration at the site of injection has also been noted [16] However little has been published on the duration of this discoloration. The aim of this study was to evaluate the duration of the visible blue skin discoloration at the injection site in the breast after SLNB.

\section{Patients and Methods}

All patients who undergo breast conserving surgery (BCS) with SLNB are reviewed annually with mammographic and clinical follow-up. $236 \mathrm{pa}-$ tients were reviewed from January 2007 to December 2009 by a single observer (JW) under uniform conditions. Over a 3-year period, all patients were assessed for skin discoloration as well as cosmetic and psychological problems at their annual review. 41 patients were reviewed more than once, in which case the change in discoloration was noted. Further long-term follow-up of persistent staining beyond December 2009 has not been undertaken.

For SLNB, immediately after induction of general anesthesia, $1 \mathrm{ml}$ of Bleu Patente V dye was injected intradermally and subdermally at the periareolar margin in the upper outer quadrant of the breast. Patients had received their injection of radioisotope the previous afternoon using the ALMANAC trial protocol [17]. All operations were performed by either surgeons PJ or SJ. PJ dilutes $2 \mathrm{ml}$ Bleu Patente V with $2 \mathrm{ml}$ saline before injecting intradermally/subdermally, and SJ injects it undiluted. Visual assessment of skin discoloration was assessed under uniform conditions and recorded subjectively by a single observer (JW) over 36 months. All patients were assessed with a 4 point scale of discoloration $(0=$ no color, 1 = faint blue tinge (fig. 1), 2 = moderately obvious blue, 3 = heavy blue color (fig. 2))

Patient characteristics, dates of operation, pathological diagnosis, surgeon details, re-excision, and ALND rates were analyzed retrospectively. Statistical analyses were performed with SPSS version 12.0 (SPSS Inc., Chicago, IL, USA). Data are presented as the mean \pm standard deviation or $\mathrm{n}(\%)$. The differences between the subgroups were analyzed by chisquare or Fisher's exact tests. A p $<0.05$ was considered significant.

\section{Results}

Of the 236 patients, 2 had undergone bilateral surgery, and 41 had been examined in consecutive yearly reviews. The mean age of the patients at presentation was 62 years (range 33-91 years). 148 patients were operated on by $\mathrm{PJ}$ who used diluted Bleu Patente V. 90 patients had operations performed by SJ who used undiluted Bleu Patente V. There was no statistically significant difference between the different techniques and persistent staining at 12 months $(\mathrm{p}=0.597)$ and 24 months $(\mathrm{p}=0.648)$.

Overall, 203 (85.3\%) patients had invasive ductal carcinoma, 25 (10.5\%) patients had infiltrating lobular carcinoma, $5(2.1 \%)$ patients had intraductal carcinoma (3 with microinvasion, 1 mastectomy and immediate reconstruction, 1 with skin tethering which was considered likely to be invasive but proved to be only ductal carcinoma in situ on final histology), $3(1.3 \%)$ patients had mucinous adenocarcinoma, and $2(0.8 \%)$ 
patients had adenoid cystic carcinoma. Re-excision for close margins was performed in $24(10.1 \%)$ patients.

A total of $50(21 \%)$ patients underwent a completion axillary node clearance (ANC) for positive SLNs. In this group, there was no statistically significant difference regarding the degree of discoloration in the first 2 years of follow-up compared to the SLNB alone group $(\mathrm{p}=0.791)$. The skin discoloration rate was slightly higher in the ALND group of patients $>36$ months after surgery compared to the nonALND group, but this difference was not statistically significant $(\mathrm{p}=0.85)$.

The ratios of skin discoloration over time are summarized in table 1 . At 12 months, no patient had grade 3 skin discoloration but $36.5 \%$ of 115 patients seen had some residual discoloration which fell to $23.6 \%$ at 24 months. At 36 months, $8.6 \%$ of patients still had discernible discoloration (table 1 ).

Of the 236 patients, 41 were reviewed twice while all others were seen just once. 17 patients were examined at 12- and 24-

Table 1. Skin discoloration rates of patients

\begin{tabular}{lccc}
\hline Grade & \multicolumn{3}{l}{ Patients, $\mathrm{n} \%$} \\
\cline { 2 - 4 } & 12 months & 24 months & $>36$ months \\
\hline 0 & $73(63.5)$ & $81(76.4)$ & $53(91.4)$ \\
1 & $28(24.3)$ & $18(17.0)$ & $4(6.9)$ \\
2 & $14(12.2)$ & $7(6.6)$ & $1(1.7)$ \\
3 & $0(0)$ & $0(0)$ & $0(0)$ \\
Total & $115(100.0)$ & $106(100.0)$ & $58(100.0)$ \\
\hline
\end{tabular}

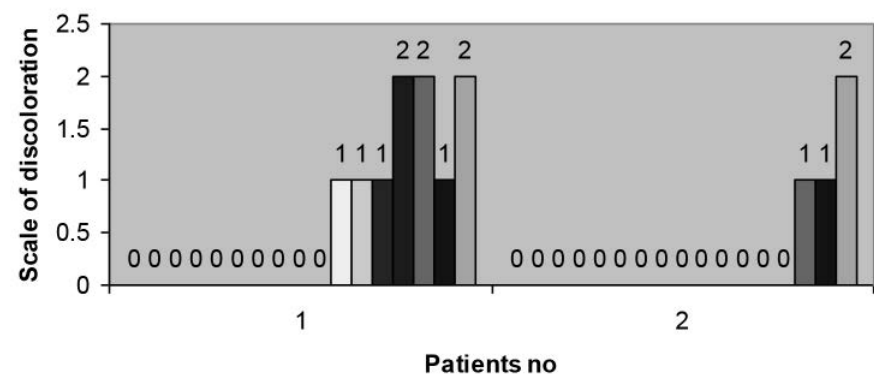

Fig. 3. Change in discoloration in 17 patients who were reviewed postoperatively over 2 consecutive years (1st and 2 nd year).

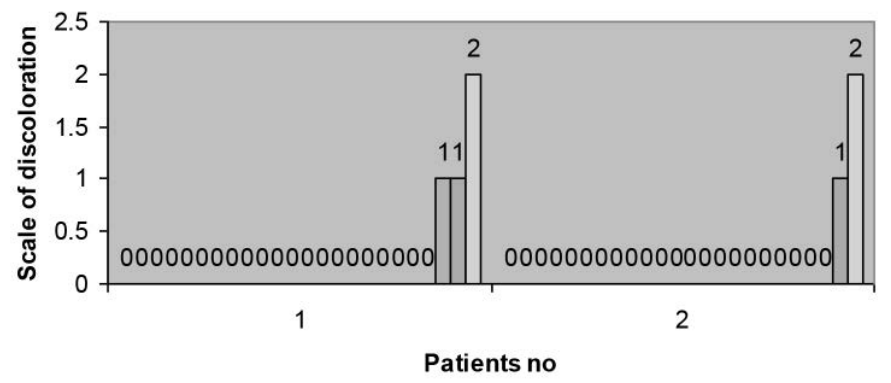

Fig. 4. Change in discoloration in 24 patients who were reviewed postoperatively over 2 consecutive years ( 2 nd and 3 rd year). month reviews. In 7 of these patients, skin discoloration was observed after 12 months, and in 5 of them skin staining had diminished by 24 months. In 2 of the 5 patients, skin discoloration was unchanged at 24 months (fig. 3). 24 patients were reviewed at 24 and 36 months post-surgery. Skin discoloration was observed in 3 of those patients at 24 months. In 1 patient skin staining decreased, and in 2 patients skin discoloration remained the same at 36 months (fig. 4).

No allergic reactions occurred postoperatively. No patient reported that the persistent staining was a cosmetic or psychological problem at follow-up.

\section{Discussion}

Anatomic studies have shown that the density of lymphatics is greater in the skin than in breast parenchyma. This means that tracers are cleared more rapidly from the skin than from parenchyma [18]. Hence, intradermal injection improves the efficacy of blue dye, because transport by skin lymphatics is more rapid and reliable than in the breast parenchyma [19]. In the present study, we used the technique of intradermal injection of patent blue for SLNB.

The safety profiles of blue dyes have been previously assessed. Side effects range from minor ones up to life-threatening anaphylaxis [20]. Isosulfan blue has been reported to cause more allergic reactions [21]. Use of the intradermal/subdermal injection technique of patent blue in SLNB may cause the additional side effect of skin discoloration at the injection site. It is possible this could be considered a cosmetic problem for some women. This should be discussed as a potential complication at the time of obtaining consent for surgery. In another study, this condition was shown to persist in $41 \%$ of patients 1 year postoperatively [12]. In our study, 36.5\% of patients had some residual discoloration at 12 months, which fell to $23.6 \%$ by 24 months. In a small percentage of patients, staining remains even longer. The skin discoloration rate decreases more quickly after the second year, but may remain after 3 years.

ALND may result in impaired lymphatic drainage of the ipsilateral breast as well as the arm. We tried to assess if ALND has an extra negative effect in the persistence of blue staining, i.e. more extensive axillary surgery might result in more damage to the lymphatic system resulting in deteriorated/delayed clearance of the dye compared to SLNB only patients where fewer lymphatic vessels are severed. We could not see any difference at all between ALND versus SLNB alone patients during the first 2 years after surgery. A slight difference appeared in the 3rd year in that blue staining was more prevalent in the ALND group, but this difference was not statistically significant.

Use of diluted or undiluted blue dye caused no statistical difference in the rate, duration, or severity of skin discoloration. Long-lasting skin discoloration may lead to disfiguring 
blue marks and cause anxiety in patients. It has been suggested that peritumoral injection causes less long-term staining. In the present study, where all injections were periareolar, none of the patients considered their skin staining to be a cosmetic or psychological problem. Goveart et al. [12] showed that after proper preoperative briefing, none of their patients considered prolonged skin staining a cosmetic or psychological problem.

The effects of completion ANC on the duration of staining of patent blue after intradermal/subdermal injection may be further evaluated in a longer and larger series.

\section{Conclusion}

The employment of a patent blue injection for SLNB identification in breast-conserving surgery for cancer patients may result in longer periods of skin discoloration than was previously recognized.

\section{Disclosure Statement}

There is no conflict of interest.

\section{References}

1 Bézu C, Coutant C, Salengro A, Daraï E, Rouzier R, Uzan S: Anaphylactic response to blue dye dur ing sentinel lymph node biopsy. Surg Oncol 2011; 20:e55-59.

2 Mansel RE, Fallowfield L, Kissin M, Goyal A Newcombe RG, Dixon JM, Yiangou C, Horgan K, Bundred N, Monypenny I, England D, Sibbering M, Abdullah TI, Barr L, Chetty U, Sinnett DH, Fleissig A, Clarke D, Ell PJ: Randomized multicenter trial of sentinel node biopsy versus standard axillary treatment in operable breast cancer: the ALMANAC Trial. J Natl Cancer Inst 2006;98:599_ 609.

3 Coster S, Poole K, Fallowfield LJ: The validation of a quality of life scale to assess the impact of arm morbidity in breast cancer patients post-operatively. Breast Cancer Res Treat 2001;68:273-282.

4 McLaughlin SA, Wright MJ, Morris KT, Giron GL, Sampson MR, Brockway JP, Hurley KE, Riedel ER, Van Zee KJ: Prevalence of lymphedema in women with breast cancer 5 years after sentinel lymph node biopsy or axillary dissection: objective measurements. J Clin Oncol 2008;26:5213-5219.

$\checkmark 5$ Teal C, Slocum J, Akin E: Evaluation of the benefit of using blue dye in addition to radioisotope for sentinel lymph node biopsy in patients with breast cancer. Breast J 2005;11:391-393.

6 Syme DB, Collins JP, Mann GB: Comparison of blue dye and isotope with blue dye alone in breast sentinel node biopsy. ANZ J Surg 2005;75:817-21.
Thevarajah S, Huston TL, Simmons RM: A comparison of the adverse reactions associated with isosulfan blue versus methylene blue dye in sentinel lymph node biopsy for breast cancer. Am J Surg 2005;189:236-239.

8 Tsopelas C, Sutton R: Why certain dyes are useful for localizing the sentinel lymph node. J Nucl Med 2002:43:1377-1382.

9 Woltsche-Kahr I, Komericki P, Kränke B, Brabek E, Horn M, Schuller-Petrovic S, Richtig E, Aberer W: Anaphylactic shock following peritumoral injection of patent blue in sentinel lymph node biopsy procedure. Eur J Surg Oncol 2000;26:313-314.

10 Mullan MH, Deacock SJ, Quiney NF, Kissin MW: Anaphylaxis to patent blue dye during sentinel lymph node biopsy for breast cancer. Eur J Surg Oncol 2001;27:218-219.

11 Wöhrl S, Focke M, Hinterhuber G, Stingl G, Binder M: Nearfatal anaphylaxis to patent blue V. Br J Dermatol 2004;150:1037-1038.

12 Govaert GA, Oostenbroek RJ, Plaisier PW. Prolonged skin staining after intradermal use of patent blue in lymph node biopsy for breast cancer. Eur J Surg Oncol 2005;31:373-375.

13 Morell RC, Heyneker T, Kashtan HI, Ruppe C: False desaturation due to intradermal patent blue dye. Anesthesiology 1993;78:363-364.

14 Koivusalo AM, Von Smitten K, Lindgren L: Sentinel node mapping affects intraoperative pulse oximetric recordings during breast cancer surgery. Acta Anaesthesiol Scand 2002; 46:411-414.
5 Van Weesem K, MeijerWS: Sentinel lymph node biopsy in breast cancer: results of intradermal periareolar tracer injection and follow-up of sentinel lymph node negative patients. Breast 2004;13:290 296.

6 Beechey-Newman N: Sentinel node and breast cancer. Eur J Surg Oncol 2004;30:226-228.

17 Barthelmes L, Goyal A, Newcombe RG, McNeill F, Mansel RE: NEW START and ALMANAC study groups. Adverse reactions to patent blue $\mathrm{V}$ dye The NEW START and ALMANAC experience. Eur J Surg Oncol 2010;36:399-403.

18 Shoei H, Aboulouz S, El Lamie I: Sentinel lymph node mapping in breast carcinoma. ASJOG 2005; 2:244-254.

19 Borgstein PJ, Meijer S, Pijpers RJ, van Diest PJ: Functional lymphatic anatomy for sentinel node biopsy in breast cancer: echoes from the past and the periareolar blue method. Ann Surg 2000; 232:81-89.

20 Masannat Y, Shenoy H, Speirs V, Hanby A, Horgan K: Properties and characteristics of the dyes injected to assist axillary sentinel node localization in breast surgery. Eur J Surg Oncol 2006;32:381-384.

21 Thevarajah S, Huston TL, Simmons RM: A comparison of the adverse reactions associated with isosulfan blue versus methylene blue dye in sentinel lymph node biopsy for breast cancer. Am J Surg 2005;189:236-239. 